\title{
Investigating the Relationship between the Performance of Human Resources and Emotional Intelligence in the Industry - Case Study: An Industrial Unit Active in the Field of Polymer Disposable Accessories for Food Packaging and Pharmaceutical Serving and Packaging
}

\author{
Somayeh Sadat Mahmoudzadeh Bakht Abad ${ }^{1}$, Mohammad Taji ${ }^{2}$ \\ ${ }^{1}$ Senior Advisor Industrial Engineering, Intelligent Decision Research Group, Tehran, Iran. \\ ${ }^{2}$ Corresponding author, Department of mining Engineering, Shahrood Branch, \\ Islamic Azad University, Shahrood, Iran \\ taji@ymail.com.
}

Abstract - Introduction: Given the identification of human resources problems in the studies, this research began with the hypothesis of the effect of emotional intelligence on communication ability and environmental perception on the level of employees' performance. Thus, itinvestigated the relationship between the level of emotional intelligence of employees and their level of performance.

Methodology: This study was conducted using analytical, survey and statistical methods. The tool needed to collect data on emotional intelligence and performance was a questionnaire completed using survey method. For comparative evaluation, two valid emotional intelligence questionnaires, developed by BarOn and Goleman, were usedwhose validity and reliability had been proven in previous studies. The localized Goleman and Bar-On Questionnaires, consisting of 33 and 90 questions, respectively, were completed for a sample of 164 people selected from a population of over 250 people.

The data on the level of performance of the employees were also distributed through the design of a performance evaluation check list with a reliability of $95.2 \%$ with using a 360 -degree method by managers, customers, equal-level forces, and subordinates.

Data were analyzed using SPSS software for statistical analysis. Cronbach's alpha coefficient was used to measure reliability, Kolmogorov-Smirnovtestwas used to measure the normality of data, hypothesis $t$ and F test was used to examine the relationship between variables and linear regression was used to estimate the relationship between variables.

Results: There was a positive and significant relationship between the level of performance of employees and Goleman`s five components. Additionally, the level of performance other than stress control and interpersonal relationships showed a positive and significant relationship with three other components of Bar-On Emotional Intelligence, including general mood, adaptability, and interpersonal relationships. According to the regression analysis, Goleman emotional intelligence explained higher level of total performance level, compared to Bar-On emotional intelligence.

Keywords: Performance evaluation, Human resource performance, Grounded data, Fuzzy Delphi, Emotional intelligence, EQ, Bar-On, Goleman, Siberya Sharing.

1-Introduction

The main goal of all organizations is to enhance the productivity in all organizational inputs. Enhancing the productivity will also be realized in the light of the increasing efficiency and effectiveness.

OECDhas defined productivity as the income divided by resources. EPAhas defined productivity in two ways:

- Productivity is maximizing the use of resources needed in production.

- Productivity is a type of thinking; we must believe that everything that can be done tomorrow may be done better today (Haghighatian and Ezati, 2015). 
From the JPC point of view, productivity is a national choice and priority and every effort to increase the productivity should lead to increased social welfare, reduced poverty, and correctly choosing and doing the works. In other words, productivity means the scientific use of national resources such as human resources and other factors of production in lowering prices, increasing market value, reducing unemployment, increasing real incomes, and increasing living standards for customers, managers and employees (Organization of Asian Productivity, 2004). The absolute value of using valuable and proportional physical assets combined with efficient human resources, will allow for the realization of planned organizational goals and increased productivity.

Without doubt, using valuable physicalcapital and assets along withefficient human resources will result in the realization of planned organizational goals and increased productivity. It has been sometimes proven thateven the presence of many physical and capital assets and valuable technical knowledge have resulted in the loss and waste of resourcesdue to inefficient human resources and poor performance. In other words, the realization and acquisition of the maximum productivity of other organizational inputs are significantly correlated with the performance of human resources and the way of employees'dealing with these inputs.

Knowledge capitals of employees are one of the most important components of organizational performance. While for the proper functioning of the organization, the existence of knowledge is necessary but not enough, the human resources in an organization increase the use of tangible assets (tools and equipment) and apply the intangible assets (Fitz-enz, 2001).

The above concept is followed by an increase in productivity and increasing productivity and human resource performance finally lead to increased satisfaction of managers' satisfaction and this satisfaction can lead to more welfare facilities, development of assets, wealth and savings.

Accordingly, special attention has been paid to the role of human resources in organizations in recent years compared to other resources of the company and researchers are looking for examining the factors that increase the efficiency of human resources. Human is considered as the most complex natural world system in management knowledge, so it can be predicted that several factors are effective in increasing the human resources 'performance of an organization or group. These factors can physically and emotionally affect the human resources and the type of his dealing with work and job responsibilities. As personality factors have more profound effects on the human resources' performance, it plays a particular importance. Among the important examples in these personality factors, we can refer to the elements that influence the person's control of the emotions and management of his relationships with other people. Therefore, along with monitoring and evaluating the human resources ' performance in the organization, factors such as the above-mentioned that indirectly affect the performance of people, can be investigated. Emotional intelligence or EQ of employees and human resources of an organization in addition to leaving individual and personality impact on people, can also be effective in work and organizational strategies.

Social and emotional competencies and capabilities are factors that determine the quality of social relationships and success in various life and professional areas (Myer and Karasu).

Therefore, this research examined the emotional intelligence of employees and the level of their performance and the relationship between these two variables.

\section{2- Statement of the problem}

The present study was conducted as a case study in an industrial unit with more than 300 employees. According to its policy in the development area, training and recruitment of human resources have faced with the issue of employees' performance evaluation and the solutions to increase it.Among the factors affecting the performance of employees is the EQ of people, which can be effective in the work performance of that person and the human resource productivity of the organization, due to the emergence of some capabilities in communication between people and their colleagues and their clients. This study was conducted to find if there is asignificant relationship between employees' emotional intelligence and their performance according to the considered indicators of the organization. This relationshiph as been examined based on two assessment methods of Bar-On and Goleman emotional intelligence and its results have been compared. The unknown aspects of the problem were the relationship between employees' performance and EQ level of employees.

\section{Independent variables}

The level of emotional intelligence of employees has been considered as the independent variable. The level of emotional intelligence was derived from Goleman and Bar-OnQuestionnaires in the form of EQ score.For a more accurate evaluation, each emotional intelligence score includes components whose scores have been calculated separately. Scores are calculated on a scale ranging from 0 to 100 and the final score along with the components, separately,have been considered as an independent variable. 
Goleman Emotional Intelligence Questionnaire includes five main components andBar-On Emotional Intelligence Questionnaire includes five main components and fifteen sub-components which have been considered as independent variables.

\section{Dependent variable}

The level of performance and productivity of human resources is dependent variable of the study. The level of performance is evaluated around two axes.

Axis 1: Observing general requirements in the ethics area and organizational commitment with a share of $40 \%$

Axis 2: Correctly performing the specialized tasks with a share of $60 \%$.

\section{3- Review of the related literature}

As most studies, the present research also,began with review of library studies and scientific articles.

Minarova (2014) considered emotional intelligence as an essential part of the competence of a manager. He has defined competence as manager's ability (consisting of three components of general and technical ability, scientific and practical skill, and individual and social maturity) and competence (power, responsibility, and duty). Arguing that the high level of managers' competence (in addition to the balance among its elements) is an important prerequisite for the success of a company in achieving its mission and vision, he has considered the emotional intelligence as the basic element of social maturity. If a company wants to succeed in the long term, it must actively cooperate with its employees as they are the only owners of its human capital (Mura 2013). Goleman (2000) has defined emotional intelligence as the ability to control and manage the emotions. It needs to be guided appropriately and effectively to cooperate with other members of a group to achieve mutual goals. He argues that the level of emotional intelligence is not determined by genetics and is not affected by growth at the beginning of a childhood. It has been proven that the quality of emotional intelligence increases in the long term and it should be noted that these qualities should be learned. Minarova (2014) viewed emotional intelligence as part of the functional element of intelligence in the sense of the ability to use emotions in social situations: recognizing the individual's emotions, motivation, self-evaluation ability, and self-movement (internal components of emotional intelligence) and simultaneously being emotional and having social skills and effective involvement for the benefit of others (Interpersonal components of emotional intelligence). Samadi (2015) examined the effect of emotional and spiritual intelligence on the job performance of 185 employees of the Iranian Oil and Gas Pipeline and Oil Telecommunications Company. He concluded that the components of interpersonal skills, adaptability, stress control, critical existential thinking, generation of personal meaning and transcendental knowledge affect the job performance.Mashayekh Bakhsh (2014) investigated the organizational conflict and its relationship with emotional intelligence in employees of Mellat Bank (Mazandaran province) in a population of 850 people. He concluded that in ranking the emotional intelligence components, the component of management and control of emotional intelligence is the most important among other components in employees and managers.Among the interpersonal conflict factors, the most important factor was the conflict with subordinate. There was a significant and positive correlation between the components of normative intelligence with each other in employees and managers.Moreover, there was a positive and significant relationship between the interpersonal conflict factors among employees with each other and among managers, while no correlation was found between the factor of conflict with manager and conflict with subordinate. There was a significant and negative relationship between the components of emotional intelligence and interpersonal conflict factors among the employees, but no relationship was found among the managers.

In their research entitled "The relationship between emotional intelligence and job satisfaction of physical education teachers, Yarmohammadi Monfared et al. (2010) found that by providing facilities and meeting the needs of teachers and by training and increasing the emotional intelligence, their job satisfactioncould be increased. The results of a study conducted by Shushtarian et al., (2009) suggested that emotional intelligence leads to self-awareness, self-management, social awareness and adaptation to work environment, and emotional intelligence has a positive and significant relationship with job satisfaction and job performance. Moreover,the results of a study conducted by Golparvar et al., (2010) showed that there is a significant and positive correlation between the components of emotional intelligence and self-evaluation and job performance. Seyed Javadin et al. (2007) also confirmed the relationship between emotional intelligence and job performance.

\section{4-Research methodology}

This research was conducted using descriptive and statistical analysis method and SPSS software.Data on the level of emotional intelligence were collected using survey method through Baran and Goleman questionnaires.Data on the level of employees' performance were collected using a checklist whose reliability was confirmed with a Cronbach's alpha coefficient of 95.2\%.Cronbach's alpha coefficient are used to measure the reliability of the questionnaire and Spearman correlation coefficient and $t$ and $F$ tests are used to examine the relationship between variables. 
The normality of data has been examined using Kolmogorov-Smirnov test.

Sampling method: convenient randomized method

Sample size determination method: Cochran formula

The employees' performance was evaluated based on the way of performing the duties and adherence to ethical and professional principles and requirements.

General performance evaluation: It was based on the adherence to the ethical and professional principles and requirements

Specialized performance evaluation: It was based on performing specialized tasks and dutiesrelated to job identification, with a necessary expertise in four areas of knowledge, skills, motivation and transfer of experience.

Statistical population: It included employees working in an industrial unit operating in the production of disposable tableware and polymer food and drug packaging. The evaluation of their performance in the third quarter of the year 2017 was used in this study. Sample size was determined to include 164 people out of a population of 286 people using Cochran formula. Considering a rate of incorrect completion of questionnaires or lack of their returning, 250 questionnaires were distributed.

\section{5-Investigating the relationship between emotional intelligence and the level of employees' performance}

Historically, emotional intelligence is rooted in the concept of social intelligence, which was first recognized by A.L Gerendyke in 1920. Since that time, psychologists have also identified other categories of intelligence. In 1970, two American psychologists, namely, Dr. Peter Salovey of the University of Yale, and Dr. John Mayer of the University of New Hampshire, presented the scientific discussion of emotional intelligence for the first time. In 1975, Howard Gardner introduced the idea of Multiple Intelligence. He introduced eight types of intelligence in two broad categories of interpersonal intelligence and intrapersonal intelligence. Many psychologists, including Gardner, argued that traditional IQ evaluation criteria, such as IQ tests, are not able to describe the cognitive abilities. The term Emotional Intelligence was first introduced in 1985 by Wayne Pine, but it was popularized by Daniel Golmen in 1995.

Most of the studies in this area have been conducted by Peter Salvoy and John Mayer in the 1990s. They concluded that the capacity to perceive the emotions is a new factor in the personality of people.

Bar-On believes that emotional intelligence is a set of abilities and skills that equip a person to adapt effectively to the environment and to succeed in life, and the trait of emotional in this kind of intelligence plays key role andmakes it to be distinguished from cognitive intelligence.

\section{5-1- Emotional intelligence level}

The tools used to collect qualitative data in the area measuring the emotional intelligence included Bar-On emotional intelligence questionnaire and Goleman emotional intelligence questionnaire.

The above-mentioned questionnaires were identified during thelibrary studies of the articles and the results of the conductedstudies. Their validity and reliability have been examined and confirmed in these studies. In his Emotional Intelligence Questionnaire, Bar-On has considered 5 components for emotional intelligence, including intrapersonal emotional intelligence, interpersonal emotional intelligence, stress tolerance, general mood and adaptability. These 5 components include 15 sub-scales.

In Goleman Emotional Intelligence Questionnaire, as with Bar-On Questionnaire, emotional intelligence includes 5 components, while none of these components is subdivided into sub-components in this questionnaire.These five components include self-awareness, self-motivation, self-control, social skills and social consciousness.In each question, each group of questions is assigned to a certain area of the components and their scores are summed up to show the final score of that component and finally the final score of emotional intelligence.

Emotional intelligence indicators based on the Bar-On questionnaire consist of 5 main components and 15 subcomponents:

1- Intrapersonal skills

- Emotional self-awareness (the ability to be aware of your feelings and emotions)

-Self-assertiveness (the ability to express the feelings, beliefs and thoughts and defend the constructive skills)

- Independence (the ability to direct your thoughts and actions)

-Self-actualization (the ability to understand your potential and attempt to do something that can be done)

- Self-respect (the ability to be aware of your perceptions, acceptancerespecting yourself) 
2- Interpersonal skills:

- Interpersonal relationships (awareness, understanding, and perceiving others' feelings, creating and sustaining satisfactory bilateral relationships characterized by emotional closeness and affiliation)

- Social commitment (being an effective and constructive member of your social group, showing yourself as a good partner)

- Empathy (the ability to recognize others' feelings, perceive their feelings and admire them)

3- Adaptability:

Problem solving (ability to diagnose and define problems and realize effective solutions)

- Realism (the ability to measure the coordination between what has been emotionally felt and what has been actually happened)

- Flexibility (ability to adapt thoughts and behavior to environmental changes and situations)

4- Stress control:

- Ability to tolerate the stress (ability to tolerate the stressful events and strong emotions positively and actively coping with stress)

- Impulse control (ability to tolerate an impulse and control your emotions)

5- General mood:

- Happiness (the ability to feel satisfied with yourself and making yourself and others happy)

- Optimism (the ability to look at life cleverly and strengthen positive attitudes even in the event of a misfortune and a negative feeling)

Emotional intelligence indicators based on the Goleman questionnaire consist of five main components:

-Self-control: The ability to manage your emotions.

-Self-awareness: The ability to be alert and accept your feelings.

-Self-motivation: The ability to deliberately develop a strong will and an optimistic behavior.

-Social vigilance: Ability to understand other feelings even if we have different feelings.

- Social consciousness: The ability to adapt your actions, behaviors and feelings to other people's expectations and feelings.

\subsubsection{Validation of emotional intelligence measurement questionnaires:}

The design of Bar-On Emotional Intelligence Test (1980) was initiated in 1980 with the question of "Why some people are more successful than others in life." In this year, the author presented the concept, definition and size of non-cognitive intelligence (Bar-on, 1988, 1992, 1996a, 1996c, 1997a and 1997b). His strategy to construct the test consists of four main steps:

1. Classification of different variables and recognizing that these variables fall under which keywords to determine effective and successful performance and also positive emotional health (based on author's clinical experiences and a review of literature on mental health).

2. The operational definition of these factors.

3- Making a plan of questionnaire to test these factors.

4. Interpreting the results and applying them for having access to reliability, factor structure and validity of test.

\section{Bar-On Emotional Intelligence Test Characteristics:}

This test has 117 questions and 15 scales. It has been implemented by Bar-On on 3831 people of 6 countries (Argentina, Germany, India, Nigeria and South Africa), which $48.8 \%$ of them were male and $51.2 \%$ were female and systematically standardized in North America.

The results of standardization showed that the test had a good level of validity and reliability.

(Source: Samei, Raheleh et al., Sina Institute for the Study of Behavioral Sciences)

The reliability of the fifteenth scales of the questionnaire was determined by Bar-On by using Cronbach's alpha coefficient and it was reported $69 \%$ to $86 \%$ with a mean of $76 \%$. Bar-On also reported its reliability as $85 \%$ after one month and $75 \%$ after four months using test-retest method.

In order to examine the validity of the questionnaire, the correlation coefficient of the scores obtained from this questionnaire with other valid emotional intelligence questionnaires was calculated and the results indicated the validity of the questionnaire (Mokhberian Nejad, 2007).

In his study on high school students in Tehran, Mokhberian Nejad (2007) has attempted to standardize the BarOn Emotional Intelligence Questionnaire.

Based on this research, the total validity of the questionnaire was calculated to be $91 \%$. In order to examine the construct validity of the questionnaire, factor analysis was carried out using principal components analysis method. 
The results showed that the fourteen factors havingan eigenvalue more than one explained $37.652 \%$ of the total variance of variables. The results confirmed the validity and reliability of the questionnaire.

As a result of standardization, this questionnaire was adjusted from 133 questions to 90 questions.

Scoring:

As options are set on a 5-point Likert scale, the scoring is done from 5 to 1 (I strongly agree with=5, and I strongly disagree $=1$ ), and in some questions with negative or inverse content, the scoring is done from 1 to 5 (I strongly agree $=1$ and I strongly disagree $=5$ ). The total score of each scale is obtained by summing up the scores of each of the questions of that scale and the total score of the test is obtained by summing up the scores of 15 scales. Obtaining higher score in this test reflects the higher success of the person on the given scale or the entire test, and vice versa. For example, obtaining higher scores on self-assertiveness scale reflectshigher selfassertiveness of the person.

The questions are uniformly distributed indifferent components. In other words, 90-item questionnaire contains 15 sub-components, each of which contains 6 questions.

Goleman EQ Measurement Questionnaire:

This questionnaire has five components. The distribution of the questions of the Goleman questionnaire is not uniform, in contrast to the Bar-On questionnaire and its number varies in each component:

Self-awareness: It includes 8 questions

self-motivation: It includes 7 questions

Self-control: It includes 7 questions

Social consciousness: It includes 6 questions

Social Skills: It includes 5 questions

The original version of this questionnaire, developed by Goleman, includes 70 questions. It was standardized in Iran by Mansouri (2001) and adjusted to 33 questions.

He obtained the internal consistency of the test as $85 \%$ by Cronbach's Alpha. In examining construct validity of the test, the correlation between the scores of Tehran university studentsin this test and those of Cooper's selfesteem test was examined on a sample of 30 people. According to the obtained data, the rate of correlation was reported as $63 \%$.

Mansouri also reported the Cronbach's Alpha coefficient for each of the sub-scales as follows:

Self-awareness: $59 \%$

Spontaneity: $59 \%$

Self-control: $54 \%$

Social consciousness: $51 \%$

Social skills: $51 \%$

Additionally, Asadi (2003) obtained the internal correlation of the test to be $84 \%$ using Cronbach's alpha. In the present study, the reliability coefficient of Goleman emotional intelligence questionnaire was calculated to be $81.5 \%$ using Cronbach's alpha method.

\section{5-2-Human resources performance level}

Quantitative and qualitative data in the field of employees' performance measurement were collected in the form of a questionnaire.

A 360-degree method was used to evaluate the performance, which includes:

Self-evaluation

Evaluation by subset force

Evaluation by an equal-level forceof other units

Evaluation by unit manager

The performance of employees has been measured in two general and specialized sections.

A) General performance: It includes adherence to the professional and ethical requirements of the workplace

B) These professional and ethical requirementsinclude four key areas as follows:

- Professional behavior and ethics

- Innovation and creativity

- Education and transfer of knowledge and experience 
- Satisfaction and motivation

Each of these four areas includes sub-categories that have been measured separately.

B) Specialized performance: It includes the correctly and sufficiently doing of the assigned tasks.

As the following items are effective in the correctly performing of the tasks and the correctlyapplying ofauthorities, the evaluation of the specialized performance of each individual is measured in the four areas and with the same weight in the final evaluation of the specialized performance. These four areas are:

Knowledge

Skill

Motivation

Transfer of experience

General performance with a weight of $40 \%$ and a specialized performance with a weight of $60 \%$ were applied in the final evaluation of performance.

Using Cochran formula, sample size was considered164 people out of a population of 286 people. Using questionnaire and performance evaluation checklist, the data were collected and categorized for them.It should be noted that performance evaluation checklist was extracted in a separate research using the concept of grounded data and the fuzzy Delphi method. With an acceptable reliability (Cronbach's alpha coefficient of $95.2 \%$ ), it was used in this study.

\section{5-3-Significance of the study}

The case study of this research was an industrial companyoperating in the production of serve disposable tableware and polymer food and drug packagingwith a history of more than 20 years.

Currently, with more than 270 employees, it is considered a medium-sized industry. The organizational levels have been defined and classified from the worker to unit management and senior management.

Such a manufacturing unit, with this volume of human resources, needs an efficient human resources management system, as this job classification, the fair distribution of duties and authorities, the distribution of organizational facilities such as rewards, motivational opportunities, etc., with this volume of human resources, require a systematic and scientific system, otherwise, it would lead into dissatisfaction, unwillingness to promote a job and acquire individual and organizational goals among the employees.

To achieve this goal and create an efficient human resources management system

The reasonsto select this case study include:

- Ease of access to data

- A history of familiarity with the company and the space of human resources governing it

- Exposure to some organizational complications in the human resources area that can be related to EQ level of employees and their performance.

Among the complications observed at the organization level in the area of human resources, we can refer tothe following cases:

- Non-transparency in the area ofaccountability and authoritiesamong the employees and managers

Due to intrinsic desire of individuals to obtain high authority and low accountability, instead of relying on meritocracy, defining the job identity and its adherenceis determined by bargaining the power of individuals and their social skills in dealing with the employer and others employees. For this reason, accountability and authority in a job changes with changing the people.

- Uncertainty and feeling of job insecurity among employees

- Due to the lack of transparency in the measurement criteria of human resource performance and the use of some marginal supportive leverages, the key for retention in the organization is not transparent to the employees.

- Non-transparency of punishment and rewards of employees

- Employees' relying on marginal capabilities such as bargaining whenfacing withproblems and organizational mismatches, rather than taking responsibility and providing corrective and preventive strategies.

- The rule of the individual work spirit among employees rather than group work and lack of considering the shared group and organizational goals 


\subsection{Statistical description}

Based on the nature of the subject andby implementingBar-On and Goleman Emotional Intelligence Questionnaires, the coding and analysis were performed. Descriptive statistics including frequency distribution table, percentage, mean and standard deviation were used and charts were plotted. Then, using descriptive statistics method, it was investigated using Spearman correlation method.

In this section, the characteristics of gender, age, and education of the 164 people were examined.

\section{5-4-1-Gender}

\begin{tabular}{lll} 
Table 1. Frequency distribution of samples based on gender \\
\hline gender & $\mathrm{f}$ & $\%$ \\
\hline male & 114 & $70 \%$ \\
female & 50 & $30 \%$ \\
total & 164 & $100 \%$ \\
\hline
\end{tabular}

Based on the above table, $70 \%$ of sampleswere male and $30 \%$ of them were female. These results have been summarized in the following Chart.

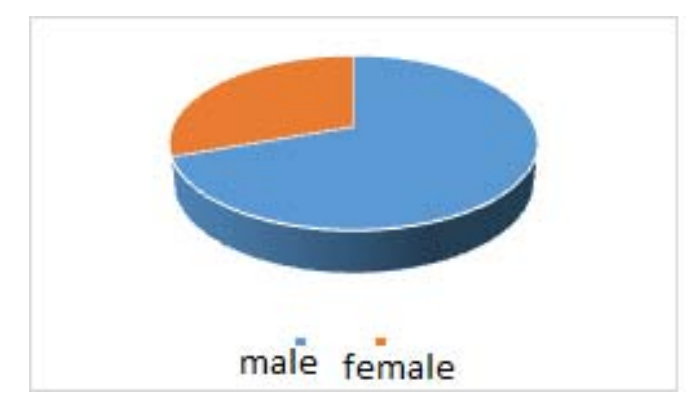

Chart 1. Relative distribution of statistical sample based on gender

\section{5-4-2-Age range}

Table 2. Age distribution of samples

\begin{tabular}{rcc}
\hline Age range & $\mathrm{f}$ & $\%$ \\
\hline 20-30 years & 85 & 51.8 \\
31-40 years & 62 & 37.8 \\
40-50 years & 13 & 7.9 \\
Over 50 years & 4 & 2.5 \\
Total & 164 & 100 \\
\hline
\end{tabular}

As shown in the table above, the age range of the sampleswere in the four ranges of 20 to 30 years, 31 to 40 years, 41 to 50 years, and over 50 years.

The highest number of samples (51.8\%)had an age between 20 and 30 years, $37.8 \%$ of themhad an age between 31 and 40 years, $7.9 \%$ of them had an age between 41 and 50 years and $2.5 \%$ of themhad an age over 50 years. These results have been shown in the following Chart. 


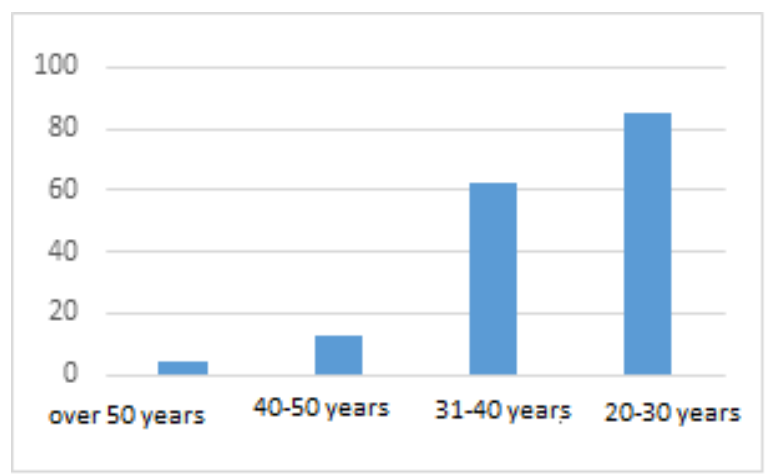

Chart 2. Relative distribution of age range of samples

\section{5-4-3-Education level}

Table 3. Frequency distribution of educational level of samples

\begin{tabular}{ccc}
\hline Education level & $\mathrm{f}$ & $\%$ \\
\hline Diploma and under diploma & 75 & 45.7 \\
associate & 6 & 3.6 \\
bachelor & 60 & 36.7 \\
master & 23 & 14 \\
total & 164 & 100
\end{tabular}

The above table suggested that $36.3 \%$ of the sample hadbachelor degree. This was is about $14.4 \%$ for students with master degree and 3.6\% for students with associate degree. Moreover, majority of the samples (45.7\%)had a diploma or under diploma degree. The distribution of the education level of sampleshas been presented in the following chart.

\section{5-4-4- Marital status}

Table 4. Frequency distribution of marital status of samples

\begin{tabular}{rrr}
\hline Marital status & $\mathrm{f}$ & $\%$ \\
\hline single & 63 & $38 \%$ \\
married & 101 & $62 \%$ \\
total & 164 & $100 \%$
\end{tabular}

According to the above table, $62.2 \%$ of the sampleswere married and $38 \%$ of them were single. These results have been summarized in the following chart.

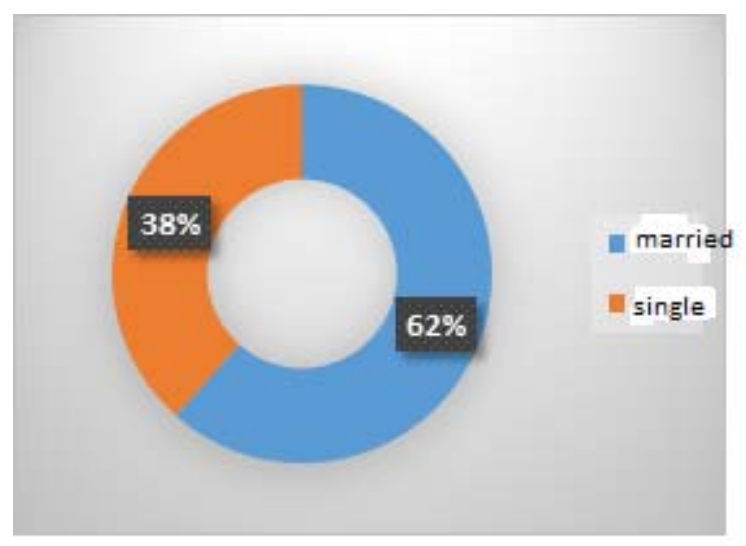

Chart 3. Relative distribution of the samples based on marital status 


\section{5-5- Normality of variables:}

Before using any test, the normality of data should be examined, since in selecting a test, we must decide whether to use parametric tests or nonparametric tests. The following steps wereused to examine the normality of the data:

Step 1: Calculation ofskewness and kurtosis

\section{Step 2 : Histogram chart}

Step 3: Kolmogorov-Smirnov test or Shapiro-Wilk test

Normality of data means that it compares the distribution of a trait in a sample (for example, an emotional intelligence score among 100 sample employees) with a distribution that is assumed for a population (for example, emotional intelligence score of all employees). If the data have a normal distribution, it is possible to use the parametrictest; otherwise, the nonparametric test should be used.

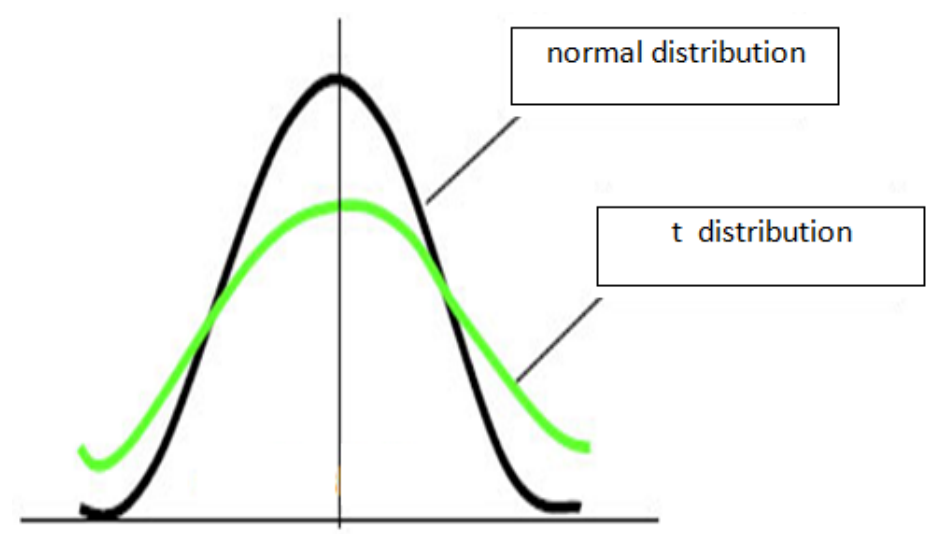

\section{5-5-1- Calculation of Skewness and Kurtosis}

First, the kurtosis and skewness of data was tested. Skewness is a criterion of symmetry or asymmetry of the distribution function. For a completely symmetric distribution, the skewness is zero and for an asymmetric distribution with a kurtosis toward higher values, the skewness is positive and for asymmetric distribution with a kurtosis to smaller values, the skewness is negative. Kurtosis represents the height of a distribution. In other words, kurtosis is a criterion of curve height at the maximum point and the kurtosis value for a normal distribution is 3 . The positive kurtosis means that theconsidered distribution peak is higher than normal distribution and negative kurtosis indicates that peak is lower than normal distribution. For example, in the distribution $t$, in which the distribution of data is more than normal distribution, the height of the curve is shorter than the normal curve. In general, if the skewness and kurtosis are not in the range $(-2,2)$, the data do not have a normal distribution. Based on the skewness and kurtosis scores in the columns of Kurtosis and Skewness, all scores were in the range $(-2,2)$. Thus, based on this method, kurtosis and skewness were normal in all variables.

\section{Histogram chart:}

Using the SPSS software, we can easily plot the histogram with a normal curve display. The histogram chart has been presented separately for dependent and independent variables.

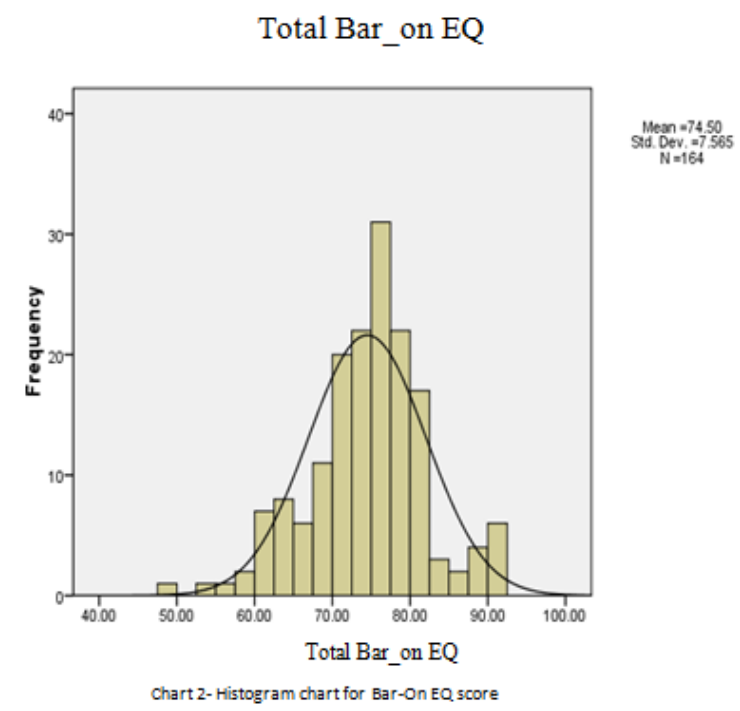


Based on the histogram charts, there was the possibility of non-normal data, for example in Bar-On EQ score and total performance. To ensure, the Kolmogorov-Smirnov test was used.

Kolmogorov-Smirnov test:

The Kolmogorov-Smirnov test is considered as one of the most important statistical tests in SPSS software.

One of the main criteria for determining the normality of the data is the Kolmogorov-Smirnov test.

When examining the normality of the data, we test the null hypothesis, stating that the data distribution is normal, at the error level of 5\%. Therefore, if the test statistic be greater than 0.05 , there would be no reason to reject the null hypothesis stating that the data are normal. In other words, the distribution of data will be normal, if the significance of the test ( $\mathrm{p}$-value $<0.05$ ), and the distribution not be normal then we must use the nonparametric test. To test the normality, the statistical hypotheses are presented as follows:

H0: The distribution of data for each of the variables is normal

H1: The distribution of data for each of the variables is not normal

Table 5.has summarized the results of Kolmogorov-Smirnov normality test.

\begin{tabular}{|c|c|c|c|}
\hline \multicolumn{4}{|c|}{ Table 5. Results of the Kolmogorov-Smirnov test } \\
\hline \multicolumn{3}{|c|}{ Tests of Normality } \\
\hline Variable & \multicolumn{2}{|c|}{ Kolmogorov-Smirnov $^{\text {a }}$} \\
\hline Statistic & df & Sig. $^{|c|}$ \\
\hline General performance evaluation & .050 & 164 & $.200^{*}$ \\
\hline Evaluation of specialized performance & .074 & 164 & .030 \\
\hline Total performance evaluation & .073 & 164 & .031 \\
\hline Bar-On1-general mood & .100 & 164 & .000 \\
\hline Bar-On2-Stress Control & .061 & 164 & $.200^{*}$ \\
\hline Bar-On3-adaptability & .082 & 164 & .009 \\
\hline Bar-On4- Interpersonal Relationship & .077 & 164 & .019 \\
\hline Bar-On5- Intrapersonal relationship & .051 & 164 & $.200^{*}$ \\
\hline Total EQ Bar-On & .077 & 164 & .019 \\
\hline Self- Awareness- Goleman 1 & .104 & 164 & .000 \\
\hline Self-motivation-Goleman 2 & .099 & 164 & .000 \\
\hline Impulse Control- Goleman 3 & .077 & 164 & .020 \\
\hline social skills-Goleman 4 & .084 & 164 & .007 \\
\hline Social consciousness -Goleman 5 & .098 & 164 & .001 \\
\hline Total EQ Goleman-Goleman & .055 & 164 & $.200^{*}$ \\
\hline
\end{tabular}

Based on the significance level in the above test, Goleman emotional intelligence score, Bar-On interpersonal score, and Bar-Ongeneral mood score had normal distribution, and other caseshad no normal distribution. Accordingly, nonparametric tests were used to continue the study process. For example, Spearman test was utilized instead of Pearson test in examining the significance of the relationship between independent and dependent variables.

\section{5-6- Correlation analysis:}

In this section, given the nature of research variables that most of them had non-normal distribution, the research hypotheses were tested by Spearman correlation methods.

Spearman correlation coefficient was introduced by Charles Spearman (1863-1945), an English psychologist and statistician in 1904. This correlation coefficient shows the level of correlation between the two ordinal variables. In other words, it is nonparametric equivalent of Pearson correlation coefficient. In this correlation coefficient, instead of using the values of variables, their ranks have been used. The relation related to Spearman correlation coefficient is defined as follows. The results of examining the relationship between the level of performance and the level of emotional intelligence have been presented in the following Table. 


\begin{tabular}{|c|c|c|c|c|c|c|}
\hline Variable & 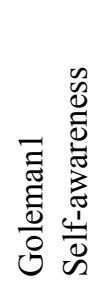 & 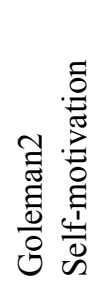 & 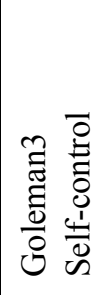 & 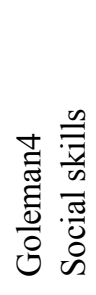 & 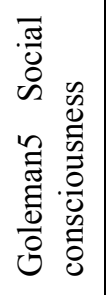 & 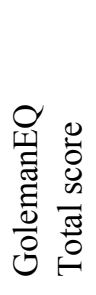 \\
\hline General performance level & 037 & .002 & .367 & .066 & .011 & 017 \\
\hline Specialized performance level & .000 & . 000 & .000 & .001 & .002 & .000 \\
\hline Total performance level & .000 & .000 & .000 & .000 & .000 & .000 \\
\hline
\end{tabular}

The null hypothesis in the correlation test is based on lack of significant correlation between the study variables and the hypotheses can be written as follows:

H0: There is no significant correlation between the variables studied.

H1: There is a significant correlation between the variables studied.

To reject the null hypothesis and confirm the significance of correlation, the significance level should be less than 0.05 .

In the table above, the correlation coefficient has been written in the first row and the significance of correlation has been written in the second row. If the significance be less than 0.05 , the correlation would be statistically significant. As seen, in some cases, the correlations between the independent and dependent variables were significant. A summary of significant relationships has been presented in the Table below.

Given the significance level of 0.05 , the general performance level had a positive correlation with all five components of Goleman emotional intelligence. It is also true for the level of specialized performance.

However, the relationship between general performance in two areas of social skills and self-control was not significant.

\begin{tabular}{|c|c|c|c|c|c|c|}
\hline Dependent variable & 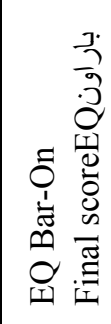 & 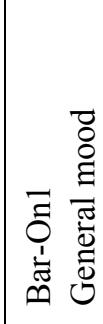 & 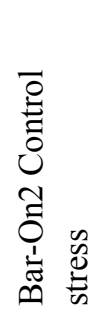 & 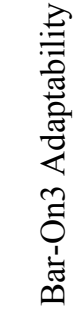 & 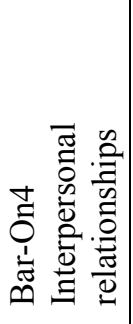 & 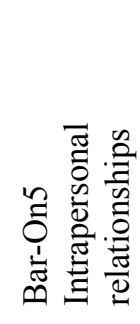 \\
\hline General performance level & .001 & .002 & .002 & .007 & .019 & .017 \\
\hline Specialized performance level & .000 & .001 & .223 & .001 & .119 & .000 \\
\hline Total performance level & .000 & .000 & .055 & .000 & .057 & .000 \\
\hline
\end{tabular}

\section{5-7- Linear regression}

Simple or Multiple Linear Regression is one of the most widely used statistical methods for analyzing data in various sciences. In regression analysis, the type of relationship between variables and whether a variable can affect other variables is examined.

In other words, "the main application of linear regression is to evaluate the factors influencing a numerical variable that has a normal distribution".

To use this statistical method, the following presumptions have been proposed:

1. Linearity of the relationship between independent and dependent variables

2. Normal distribution of error values

3. Independence of error values

4. Normal distribution of dependent variable 
The challenging issue is to determine if the presumption is normal. The question iswhich one should be considered as the "initial presumption" of linear regression: normal distribution of a dependent variable or the normal distribution of error values ? As stated, in some studies, the normal distribution of the "dependent variable" is expressed as a precondition for the use of linear regression. However, Kyani does not consider the normal distribution of dependent variable as a "necessary condition" for using linear regression and has considered the normal distribution of error values. This analysis seems to be closer to reality. Other studies have considered the use of linear regression as one of the "basic" preconditions for the use of linear regression and all agree that "if this precondition is not met, the regression cannot be used".

How the normal distribution of the dependent variable can be analyzed? It should be re-emphasized that the normal distribution of error values is the precondition (along with the independence of errors and the nonlinearity of independent variables) for using simple or multiple linear regressions. The normal distribution of the variable as a secondary condition is proposedin non-normal distribution of error. Moreover, as stated, if the error values do not have normal distribution, the conversion of the dependent variable with traditional methods or the box-cox method might solve the problem. As seen, the terms "possible" and "dependent variable" have been used here. Thus, even with the normal distribution of the dependent variable (either from the beginning or through the conversion), it is possible to use linear regression (due to the absence of one of the three conditions for the normal distribution of error values, lack of multicollinearitybetween the independent variables and the independence of the errors). Therefore, for the use of linear regression, the distribution of error values must be normal. If this precondition is not met and the dependent variable has a normal distribution, it will be impossible to use this statistical method because it is not possible to use conversion. In the case of non-normal distribution of the dependent variable, there is the possibility of normalizing it to allow the distribution of error values to be normaland use linear regression (Behnam Far and Rasti, 2015).

In this study, linear regression to extract the explanatory level of variable of the general performance AK score as the dependent variable, based on the variables of the EQ score according to Goleman and Bar-On, has been estimated, separately. It should be noted that in the linear regression, Ln of the total performance variable is used due to the non-normality of the total performance score variable. The Model Summary table represents the summary of the model. This table shows the values of $\mathrm{R}$ and $\mathrm{R} 2$. The $\mathrm{R}$ value of 0.473 indicates a simple correlation between the two variables, that is, the intensity of the correlation between the two variables. As $R$ value indicates, there is a strong correlation between two variables.

The R2 value indicates how much of the dependent variable (total performance level) can be explained by the independent variable (EQ level). Here, Goleman emotional intelligence variable could explain $22.4 \%$ of the variations in the variable of level of knowledge of all employees. The figure for the Bar-On emotional intelligence variable has beenreduced to $16.3 \%$

\begin{tabular}{|c|c|c|c|c|c|}
\hline \multicolumn{7}{|c|}{ Model Summary - Golman EQ } \\
\hline Model & $\mathrm{R}$ & R Square & $\begin{array}{c}\text { Adjusted R } \\
\text { Square }\end{array}$ & $\begin{array}{c}\text { Std. Error of } \\
\text { the Estimate }\end{array}$ & Durbin-Watson \\
\hline 1 & $.473^{\mathrm{a}}$ & .224 & .219 & .03108 & 1.930 \\
\hline
\end{tabular}

\begin{tabular}{|c|c|c|c|c|c|}
\hline \multicolumn{7}{|c|}{ Model Summary -Baron EQ } \\
\hline Model & $\mathrm{R}$ & R Square & $\begin{array}{c}\text { Adjusted R } \\
\text { Square }\end{array}$ & $\begin{array}{c}\text { Std. Error of the } \\
\text { Estimate }\end{array}$ & Durbin-Watson \\
\hline 1 & $.404^{\mathrm{a}}$ & .163 & .158 & .03228 & 1.918 \\
\hline
\end{tabular}

\section{Results}

According to the results of statistical analysis presented in above tables, the following results are obtained:

Goleman:

Considering the significance level of 0.05 , the general performance level had a significant and positive correlation with all five components of Goleman emotional intelligence. It is also true for specialized performance level. 
However, the relationship between general performance in two areas of social and self-control skills was not significant.

Bar-On

Out of 5 main components of the Bar-On EQ measurement, three components of general mood, adaptability and interpersonal relationships with a probability of over $99 \%$ had a significant relationship with total performance.

These three components had a significant relationship with both the general performance variable and the specialized performance variable.

The significance level of the relationship with the general performance was weaker in the components of intrapersonal and interpersonal relationships and its probability was $95 \%$, but its relationship with specialized performance variable, the significance level of the relationship with the probability of more than $99 \%$ for all three components was increasing.

The components of stress control and interpersonal relationships with general performance had a significant relationship, but they did not show a significant relationship with the specialized performance and consequently, they had a significant relationship with the total performance.

All significant relationships identified between the variables of the Bar-On EQ five components and the general, specialized, and total performances were directly correlated. In other words, with the increasing of the independent variable, the dependent variable also increased, and vice versa.

Moreover, during the statistical analysis by the mentioned method, among all sub-components of EQ in the BarOn questionnaire, all components, except for the following cases, had a significant relationship with the total performance variable:

Self-control: It had a significant relationship (more than 99\%) with general performance, but it did not have a significant relationship with specialized and total performance.

Problem solving: It had no significant relationship with any of the general, specialized, and total performance variables.

Responsibility: It had a significant relationship (more than 99\%) with general performance, but it did not have a significant relationship with specialized and total performance.

Empathy: It had no significant relationship with any of the general, specialized, and total performance variables.

According to the linear regression results, Goleman emotional intelligence level, compared to Bar-On emotional intelligence level, explained the greater share of the employees' performance level.

\section{References}

[1] Mohamad, M. Jais, J. Emotional Intelligence and Job Performance: A Study Among Malaysian Teachers, 7th International Economics \& Business Management Conference, 5th \& 6th October 2015, Procedia Economics and Finance 35: 674 - 682, 2016.

[2] Basogul, C. Ozgür, G. Role of Emotional Intelligence in Conflict Management Strategies of Nurses, Asian Nurs Res (Korean Soc Nurs Sci). Sep;10(3):228-233. doi: 10.1016/j.anr.2016.07.002. Epub 2016 Jul 19, 2016.

[3] Jameson A. Carthy A. McGuinness C. McSweeney F. Emotional intelligence and graduates - employers' perspectives, 2nd International Conference on Higher Education Advances, Procedia - Social and Behavioral Sciences 228:515-522, July 2016.

[4] Haghighatian, M., \& Ezati, Y. An Investigation into Effective Factors on Human Resources Productivity (Case Study: Region 11, Islamic Azad University, Iran). In: ProcediaSocial and Behavioral Sciences, 205, 601-607,2015.

[5] Martina, M. Denisa M. Mariana S., Emotional Intelligence of Managers, Procedia Economics and Finance26, 1119 - 1123, 2015.

[6] Altındga,E. and Kösedağı, Y.(2015) The Relationship between Emotional Intelligence of Managers Innovative Corporate Culture and Employee Performance, in Procedia - Social and Behavioral Sciences 210:270-282, 2015, 4 th International Conference on Leadership, Technology.2015.

[7] Ros Bangun Y. Ratri Iswari K. Searching for Emotional Intelligence Measurement in Indonesia Context with Innovative Approach, in: Procedia - Social and Behavioral Sciences 169:337-345 - January 2015 , The 6th Indonesia International Conference on Innovation, Entrepreneurship and Small Business, 12 - 14 August 2014.

[8] Shooshtarian Z. Ameli F. Amini Lari M., The Effect of Labor's Emotional Intelligence on Their Job Satisfaction, Job Performance and Commitment, In: Iranian Journal of Management Studies (IJMS, Vol.6, No.1, pp:27-43, January2013.

[9] Aggarwal R. Selection of IT Personal through Hybrid Multi-attribute AHP-FLP approach, In: International Journal of Soft Computing and Engineering (IJSCE), 2(6), 11-17, 2013.

[10] Sadat Khoshouei, M., Oreyzi, H. R., Noori, A. The Eight Managerial Competencies: Essential Competencies for Twenty First Century Managers, In: Iranian Journal of Management Studies (IJMS), 6(2), 131-152, 2013.

[11] Bassett, M. L., Ramsey, W. P., \& Chan, C. C. Improving medical personnel selection and appointment processes, In: International Journal of Health Care Quality Assurance, 25(5), 442-452, 2012.

[12] Lala P. I. \& Miculeac M. Analiza economico-financiara, editie revizuita si adaugita, Timisoara: Editura Univercitatii de Vest Mathis RI, Nica PC, Rusu C, Managementul resurselor umane, Bucuresti: Editura Economica, 2012.

[13] Goldkuhl, G. \& Cronholm, S. Adding Theoretical Grounding to Grounded Theory: Toward Multi-Grounded Theory, In: International Journal of Qualitative Methods, 9(2), 187-205, 2010.

[14] Lin H. T. Personnel Selection using analytic network Proccess and Fuzy Data Envelopment Analysis Approaches, In: Computers \& Industrial Engineering, 59, pp. 937-944. 2010.

[15] Kelemenis, A. \& Askounis, D. A New Topsis-based multi-criteria Approach to Personnel Selection, In: Expert Systems with Applications, 37(3), 999-5008, 2010.

[16] Grisham T . The Delphy technique, a method for testing complex and multifaceted topics, In: International Journal of Managing Projects in Business,2(1): 112-130. 2009. 
[17] Byars, L.I \& Rue, L.W. Human Resource Management. 9 th Edition. New York: Mc GrawHill, 2008.

[18] Delucca, D. Performance Appraisal for at-will Employees, Personal Interviews, July 8-9, 2008.

[19] Morgan, R. M. \& Hunt, S.D.HRM: Conceptualization and Scale Development, European Journal of Marketing: Vol. 39 no. 11, pp. 1264-1290, 2007

[20] Wu, W.-W., \& Lee, Y.-T. Developing global managers' competencies using the fuzzy DEMATEL method. Expert Systems with Applications, 32, 499-507,2007.

[21] Francesco, A.M.and B. A. Gold. International Organizational Behavior: Text, Cases, and Skills, 2nd edition. Upper Saddle River, New Jersey: Pearson Prentice Hall, 2005.

[22] Ivancevich, J. M. Human Resource Management, (9th edition), McGraw Hill/Irwin Companies, New York, 255-287,2004.

[23] Newton, L., \& Schmidt, D. Wake-up Call, Thomson South-Western, Mason, OH, 2004.

[24] Loo, R. The Delphy Method: A Powerful Tool Strategical Management, Policing An International Journal of Police Strategies \& Management, Vol. 25, No. 4, P. 762-769, 2002.

[25] Nakata, C. and K. Sivakumar, "Instituting the Marketing Concept in a Multinational Setting: The Role of NationalCulture," Journal of the Academy of Marketing Science, Vol. 29, 2001.

[26] Fitz-en, J, The Rol of Human Capital. New York: American Management Association, 298, 2001.

[27] McCarty M. Caravan T. 360 Feedback and Proccass: Performance Improvement and Employee Career Development, In: Journal of European Industrial Training, PP.5-3, 2001.

[28] Bar-On, R. Emotional and Social Intelligence: Insights from the/Emotion Quotient Inventory. In R. Bar-On \& J. Parker (Ed's.), The Handbook/of/Emotional/Intelligenc: Theory, Development, Assessment and/Application/at/Home, School and in the Workplace. San Francisco: Jossey-/Bass, pp. 363-88, 2000.

[29] Foot, M. \& Hook, C. Introducting Human Resource anagement. Longman, 1999.

[30] Bar-on, R.A. Bar-on Emotional QuotientInventory (EQ-I): Technical/Manual Toronto, Canada: Multi-Health Systems, 1997.

[31] Goleman D. Emotional Intelligence What It Can Matter/More Than/IQ. New Yourk : Bantam Book, 2005.

[32] Carell Micheal R and et al. (1992), Personnel Human Resource Management, Mac Millan Publishing.

[33] Casio, W., (1991), Applied Psychology in Personnel Management, (4th edition), Prentice-Hall, Upper Saddle River, NJ.

[34] Boyatzis, R. E. (1982). The Competent Manager: A Model for Effective Performance. John Wiley \& Sons. New York.

[35] Hofstede, (1980) G., Culture's Consequences, Sage, Beverly Hills

[36] Goleman, D, Emotional Intelligence why it can matter more than IQ, London, Bloomsbury Publishing PLC, 1995.

[37] Saheb_azamani, M., Farahani, H., Mehrbani, E., Shahbazi, M.Y., Investigating Validity and Reliability of Evaluation Based On 360 Degree Method In Clinical Evaluation of Nursing Students, Journal of Islamic Azad University of Medical Sciences, Winter 2017, Volume 26, Issue 4: Pages 264 to 270

[38] Ebrahimi, M., Mobini Dehkordi, E., Analyzing the Role of Performance Evaluation System in Organizational Productivity Using Grounded Data Theory. Journal of Human Resource Management Research, Imam Hussein University, Autumn 2016, Eighth Year, Number 3 (25): Pages 59-81.

[39] Behnamfar, R., Rasti, A., Linear regression, normality of the distribution of error values, or normality of the dependent variable? Iranian Journal of Education in Medical Sciences, 6, 7 (33): pages 263-265.

[40] Amirinia, M., The Relationship Between Baron's Emotional Intelligence Questionnaire and Psychological Defense Mechanisms. Mellat Bank and Melli Bank Training Center, 2015.

[41] Samadi, R. Investigating The Effect of Emotional and Spiritual Intelligence on Job Performance of Iranian Oil Pipeline and Telecommunication Company Staff, Islamic Azad University - Science and Research Branch of Ayatollah Ali, Farsi Theses, 2015.

[42] Osouli Ghareh Aghaji, Sh., Sanayeiae, A., SaieadAbadi, M.R., Presentation of an Extended Model of the Impact of Electronic Culture Factor on Market Regulation and Pricing of Goods and Services, Modern Marketing Research Quarterly, Atumn 2016, Volume 6, Issue 3, Issue 22: Pages 53-66.

[43] Fathi Ashtiani, A., Dastani, M., Psychological tests - personality and mental health. Be'athat Publications., 2016

[44] Behzadi, H., EsmaieelZadeh, M. H., Investigating of The Status and Relationship between Social Intelligence and Job Performance of Managers of Astan Quds Razavi Libraries, Journal of Libraries and Information Science, 2015, Organization of Museums and Documentation Center of Astan Quds Razavi, Volume 18, Number4, (sequential 72): Pages 3-30.

[45] Safari, J., Mehdizadeh, M., Azizi, A. R., Designing a Model Based on Criteria for Selection of Employees and Estimating Organization Performance., Quarterly Journal of Human Resource Management Research Imam Hussein (AS),7 (4), pages 141-166, 2015.

[46] Mashayekh_Bakhsh, L., Investigating Organizational Conflicts and Their Relationship with Emotional Intelligence in Mellat Bank Employees (Mazandaran Province). Islamic Azad University - Science and Research Branch of Ayatollah Amoli, Farsi Thesis, 2014.

[47] Zargaripour, H. A.,The Relationship between Emotional Intelligence and Students' Quality of Life - Case Study: Islamic Azad University, North Tehran Branch, M.Sc. Thesis, 2014.

[48] Poursaiead, S. M., Ashouri, J., Creating a Model for Personnel Selection Based on the Iranian Islamic Model of Progress, Human Resource Management Research, Imam Hussein University of Technology, Vol. 6, No 3, 1-25, 2014.

[49] Zrea, Z., Bakhtiary, R., Nourizadeh, M., Analyzing the Results of Al-Zahra University Staff Performance Evaluation in 2012, First Edition, Tehran, Azal Publications, Winter 2013.

[50] Tavakoli, H., Fayaz, M., Hasannezhad, M., Investigating the Performance of Rangeland Plans of Khorasan Razavi Province Using Fuzzy Delphi Approach and Multi-Criteria Decision Making Models, Journal of Economic and Agricultural Development, Spring 2013, Volume 27, Volume 1, Pages 37-50.

[51] Sapvand, R., Souri, F., Investigating The Effect of Emotional Intelligence on Staff Performance Case Study of Staff of Lorestan University, Second National Conference on Accounting, Financial Management and Investment, Golestan Province, Gorgan-February 2013.

[52] Keyzouri, A. H., An Effective Employee Performance Assessment System; Foundations, Approaches and Methods, (PhD Thesis), Shahid Beheshti University, 2013.

[53] Aghdasi Anvari, S., Norouzzadeh, R., Factors Affecting Human Resources Empowerment. Journal of Human Resource Management Research, Imam Hussein University, 5 (1), pages 197-222, 2013

[54] Kaffashpour, A., Alizadeh Zavarem, A., Using of Fuzzy Delphi Analytical Hierarchy Process (FDAHP) and Hierarchical Cluster Analysis (HCA) in R model. F. Um. (RFM) to Determine the Value of a Customer Lifetime, Modern Marketing Research, Fall 2012, Volume 2, Issue 3, Number 6 (6) Pages: 51-68.

[55] Chitsaz, E., Zolfagharzadeh, M. M., Ghiasi Nadoushan, S., Developing a Model of Core Competencies for Cultural and Social Managers of Universities in Islamic Iran, Management in Islamic University 2, Summer 2012, Vol. 1, No. 2, Pages 27-48. 
[56] Amirzadeh Behbahani, R., Yaghoobi, Z., Evaluation of Staff Performance of National Iranian Oil Products Distribution Company of Ahvaz Region Using Analytical Hierarchy Process, Journal of Industrial Management, Faculty of Humanities, Islamic Azad University, Sanandaj Branch, Spring2012, Volume 7, Number 19, Pages: 97-107.

[57] Habibi, A., Zabet, M. R., Investigating the Impact of Performance Evaluation on Human Resources Improvement in Naja Headquarters. Pars Modir Research Journal, No. 1, pp. 111-122, 2012.

[58] Sasani moghadam, Sh., Bahrololoum, H., The Relationship between Emotional Intelligence and Psychological Skills of Female Students of Shahroud University of Technology. Journal of Science, Research, Vol. 1, No. 17, pp. 27-40, 2011.

[59] Ahadi, H. R., Ghazanfari Rad, F., Presenting a Combined Model of Fuzzy Multi-Criteria Decision Making Methods for Locating a Specialized Railway Industrial Town, Journal of Operations Research and Its Applications, Winter2012, Eighth Year, Number 4 (31), Pages: $1-11$.

[60] Mahmoudzadeh, B., Mallahi, A., Comparative Study of Emotional Intelligence of Elementary Teachers by Their Gender, Qeshm Azad University, 2011 .

[61] Haghighi, M., Gharleghi, E., Mirasadi, S., A survey of relationship between the characteristics of mission statement and organizational performance (Case of: food industries in Tehran), Journal of Transformational Management, 2010, Volume 2, Number 4, 166-186.

[62] Yarmohammadi Monfared, S., Hemmatinezhad Touli, M. A., Ramezani nezhad, R., The relationship between emotional intelligence and job satisfaction of physical education teachers. Sport Management, Fall 2010, Article 3, Volume 2, Number 6, pp. 47-65.

[63] Golparvar, M., Khaksar, F., The Relationship between Emotional Intelligence and Job Performance of Isfahan Industrial City Factors. Daneshvar Research Quarterly Journal of Behavior, Clinical Psychology and Personality, Shahed University, May 2009, Volume 17, Number 40, pages 19-34, 2010.

[64] Seyedi, S. M., Akbari, A. R., Performance Management and its Impact on Increasing Human Resource Productivity, Yadman Quarterly Journal, 2009, Yadman Structure Company, No. 53, p. 58.

[65] Shoushtarian, Z., Ameli, F., Amin Lari, M., The Effect of Emotional Intelligence on Job Attitude and Job Performance. Journal of Healthy Work, Second Year, No. 7, pp. 47-52, 2009.

[66] Rahnavard Ahan, F., Factors Influencing the Performance of Iranian Public Sector Organizations. Journal of Humanities and Social Sciences Management, Vol. 8, No. 4 (31 consecutive), 100-77, 2008.

[67] Sobhaniezhad, M., Yoozbashi, A. R., Emotional Intelligence and Management in the Organization (Theoretical Basics, Training Methods and Measurement Tools, Yastaron Publications, 2008.

[68] Mokhberian nezhad, R., Validation of Baron's Emotional Intelligence Questionnaire in High School Students in Tehran. M.Sc., Faculty of Psychology and Social Sciences, Islamic Azad University, Central Tehran Branch, 2007, Bibliography 179-181.

[69] Seyed javadin, S. R., Nikpour, H., The Effect of Emotional Intelligence on Employee Performance in Social Security Organization, 2006 .

[70] Besharat, M. A., Investigating Emotional Intelligence on Social Relationship Sufficiency. Journal of Psychological Studies, Faculty of Educational Sciences and Psychology, Alzahra University, Volume 1, Number2 and 3, Pages 25-38, 2005.

[71] Hekmatnia, H., Moosavi, M. N., Factor Analysis and Integration of Indicators in Determining Factors Affecting Human Development of Iranian Areas. Journal of Geography and Development, pages 55-70, 2005.

[72] Asadi, j., Borjali, A., Jamhari, F., The Relationship between Emotional Intelligence, Job Burnout, and Mental Health of Iran Khodro Employees. Counseling News and Research, Volume 6, Number 22, pages 41-56,2005.

[73] Kalantari, Kh., Data processing and analysis in socio-economic research. Tehran, Sharif Publications,2003.

[74] Azar, A., Faraji, H., Fuzzy Management Science, Iran Center for Productivity and Studies, 2008, Publications Society.

[75] Samooiae, R., Ranslation and standardization of the emotional intelligence test. Sina Behavioral Science Research Institute (Ravan Tajhiz), 2002.

[76] Mansoori, B., Standardization of SiberiaSharing Emotional Intelligence Test in Tehran University Students. Unpublished Master Thesis, Allameh Tabatabai University, Faculty of Psychology and Educational Sciences,2001.

[77] Ahmadvand, M. A., Psychology of Exceptional Children, Tehran, 1996, Payam Noor Publishing.

[78] Fani, A. A., 360-degree feedback. Performance Evaluation / Development Management, Tadbir Monthly, No. 147, 2003.

[79] Torabi, M., The Relationship between Emotional Intelligence and Performance of Intermediate Managers of Homa Hotel Group. M.Sc., Faculty of Psychology and Educational Sciences, Allameh Tabataba'i University, 2003.

[80] Rahnavard, F., Factors Influencing the Performance of Iranian Public Sector Organizations, Journal of Humanities and Social Sciences Management, Vol. 8, no. 4 (31 consecutive), 77-100.

[81] Performance Management and its Impact on Increasing Human Resource Productivity, Yadman Quarterly Journal, Tehran Yadman Sazeh Company, No. 53, pp: 53.

[82] Sa'atch, M.,: Kamkari, K., Askarian, M., Psychological tests,VirayeshPublishing, 2010.

[83] Robbins, S. P., :Organization Theory: Structure, Design, and Applications, Alvani, M., DanaieaFard, H.,Tehran, Safar Publications, First Edition, page 480.,2008.

[84] Hajloo, M.,: Emotional Intelligence: Measurement and nurturing practices. 2014, Ghasideh Publications.

[85] Ataiee, M., Fuzzy Multi-Criteria Decision Making, Book of Industrial Engineering, Second edition, Shahroud, Shahroud University of Technology Publications, February 2017.

[86] Danayieafard, H., Emami, M., Qualitative Research Strategies: Reflection on Fundamental Data Grounded Data Theory. Management Thought, 1 (21) Pages 69-97, 2007.

[87] Sarmad, Z., Bazargan, A., Hejazi, E., Methods in Research in Behavioral Sciences, Tehran, 2006, Nashr Agah Publications.

[88] Ghafarian, V., Dehghani Poudeh, H., Scientific theorizing in managerial studies and providing a hands-on experience. Management Research in Iran, 10, pp. 151-167, 2006.

[89] Mansouian, Y., Grounded Theory (Context Theory), Conference on Information Science Challenges at University of Isfahan, Comprehensive Management Site, 2006.

[90] Bradberry, T., Greaves, J.: The Emotional Intelligence Quick Book, Ganji. M., Ganji, H., Tehran, Savalan Publications, 2005.

[91] Alvani, S. M., Public Management, Ney Publications, 3th Edition, Tehran, 2015.

[92] Golman, D., :EQ Parsa, N., Roshd Publications, Tehran, 2001. 